\title{
Microstructural, Chemical and Mineralogical Analyses for Understanding the Geotechnical Properties of Clayey Soils
}

\section{Yvette Tankpinou Kiki ${ }^{1,2 *}$, Nadia Saiyouri'1, Victor Gbaguidi², Yannick Anguy ${ }^{1}$, Cécile Gaborieau${ }^{1}$, Richard Fabre ${ }^{1}$}

${ }^{1}$ Institut de Mécanique et d' Ingénierie (I2M), Université de Bordeaux, Talence Cedex, France

${ }^{2}$ Laboratoire d' Energétique et de Mécanique Appliquée, Université d’Abomey-Calavi, Cotonou, Bénin

Email:*yvette-sedjro.tankpinou@u-bordeaux.fr, nadia.saiyouri@u-bordeaux.fr

How to cite this paper: Tankpinou Kiki, Y., Saiyouri, N., Gbaguidi, V., Anguy, Y., Gaborieau, C. and Fabre, R. (2016) Microstructural, Chemical and Mineralogical Analyses for Understanding the Geotechnical Properties of Clayey Soils. Journal of Minerals and Materials Characterization ana Engineering, 4, 305-319.

http://dx.doi.org/10.4236/jmmce.2016.46027

Received: September 6, 2016

Accepted: October 16, 2016

Published: October 19, 2016

Copyright $\odot 2016$ by authors and Scientific Research Publishing Inc. This work is licensed under the Creative Commons Attribution International License (CC BY 4.0).

http://creativecommons.org/licenses/by/4.0/

\section{(c) (i) Open Access}

\begin{abstract}
This paper presents a study research in the laboratory of three clayey soils from the depression of the Lama, a tropical climate area where disorders appear on construction and roads. Samples were tested to establish the relationship between their mineralogy and their geotechnical properties. On the three clayey soils, analyses were performed to characterize the macroscopic behavior (physical tests, free swelling test and compressibility tests) and the microstructural, chemical and mineralogical characterizations by thermal analysis, chemical analysis, X-Ray diffraction, Scanning Electron Microscopy observations complementary X-ray EDS analyses. At first glance, the results of physical and compressibility tests appear not to be consistent with the free swelling test results. Indeed, these results highlighted differences in the behaviors of the samples because the swelling potential revealed by the results of physical and compressibility test does not follow the same trend as the one given by the free swelling test result. The main clay minerals in the studied clayey soils varied from fibrous clays (palygorskite) to bestknown clays such as smectite and kaolinite. Microstructural, chemical and mineralogical analyses allowed to understand and explain the different trends obtained by the different types of geotechnical characterization tests of studied clayey soils.
\end{abstract}

\section{Keywords}

Geotechnical, Mineralogical, Microstructural, Free Swelling Index, Smectite, Palygorskite, Clayey Soils

\section{Introduction}

Expansive soils are widely distributed in the world and particularly in tropical areas 
where their formation is related to contrasting seasons. Changes in volume of clayey soils represent the principal cause of damage to an important number of buildings and civil engineering works [1]-[3]. In tropical areas, the alternation of seasons (dry and rainy) promotes variations of clayey soils volume resulting in shrinkage/swelling cycles. Several studies based on laboratory tests focused on the cycling behavior of clays [4]-[6]. Many classifications of clayey soils in relation to their sensitivity to water and their swelling and shrinkage potential have been established [7]. Authors studied the influence of shrinkage/swelling cycles on clayey soils and showed different behaviors according to the mechanical initial state and the mineralogical composition [8] [9].

Several studies have focused on the characterization of soils by the realization of different kinds of geotechnical tests [4] [10] [11]. Most of these studies have led to the development of correlations between the physical parameters. The purpose of this study is to do, in addition to a macroscopic characterization, a microscopic scale characterization to better understand the results from macroscopic experiments. So, three clayey soils were sampled in order to be subjected to different tests. Geotechnical tests were complemented by other characterization methods that are less commonly used in civil engineering. Two classes of methods were thus jointly used: 1) measurement of macroscopic properties relying on physical test, free swelling test and compressibility test and 2) microscopic study including thermal analysis, chemical analysis, X-Ray diffraction (XRD), Environmental Scanning Electron Microscopy (ESEM) and X-Ray microanalysis. The collected information/data are cross-checked in order to have a complete understanding the most relevant characterization.

\section{Materials}

The three studied clayey soils are located in the depression of the Lama in southern Benin. Figure 1 shows the geological map of the studied area, which belongs to the coastal sedimentary basin part of the geological province known as the "Bay of Dahomey". In this area, clayey soils, lining the bottom of the depression of the Lama, developed from the middle Eocene formations. The studied area is limited by the longitudes $1^{\circ} 7$ and $2^{\circ} 05$ east and latitudes $6^{\circ} 60$ and $7^{\circ} 00$ north. The location of the sites referred to as Lama1, Lama2 and Lama3, where the clayey soils were sampled is shown in Figure 1.

\section{Macroscopic Characterization}

\subsection{Methods}

\subsubsection{Physical Tests}

The following physical tests were carried out according the following standards (all test were performed assuming common French Standard): Moisture content (NF P 94-050), sieve analysis (NF P 94-056 and NF P 94-057), Atterberg limits (allowing the determination of the Plasticity Index (NF P 94-051), effective shrinkage characteristic on undisturbed soil sample (XP P 94-060-2) and methylene-blue absorption test (NF P 94-068). 


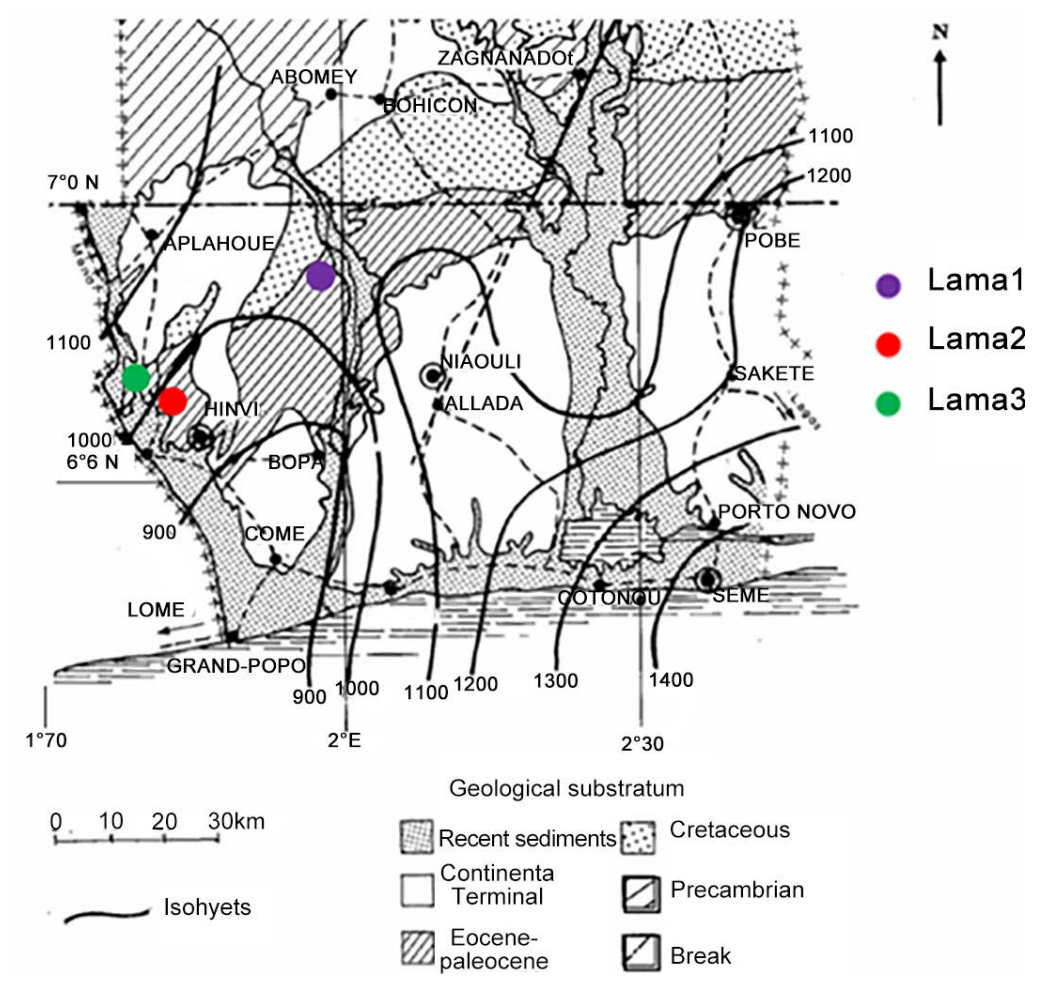

Figure 1. Geological Map [12] and location of the sampled sites.

The Unified Soil Classification System (USCS), based on the granularity and plasticity of soils, was used [13].

\subsubsection{Free Swelling Test}

The free swelling test consisted in soaking the material, sieving it under water through a sieve of 400 microns, and drying it in an oven at $105^{\circ} \mathrm{C}$. Then, $2 \mathrm{~g}$ of dry powder was introduced into a measuring cylinder and its initial volume $\left(\mathrm{V}_{\text {initial }}\right)$ was determined. The sample was last introduced into a test tube containing water: the final volume was measured after 24 hours $\left(\mathrm{V}_{\text {after24h }}\right)$.

$$
\text { Free swelling index }=\frac{\mathrm{V}_{\text {after24h }}-\mathrm{V}_{\text {initial }}}{\mathrm{V}_{\text {initial }}} \times 100
$$

This test is based on the same principle as the measure of the free swelling index according to the XP P 84-703 standard. Using this principle [10], Haas et al. obtained reliable measurement which could be correlated to the type of the clay minerals and to methylene blue values.

\subsubsection{Compressibility Tests}

Compressibility tests were performed according to the NF P 94-090-1 standard. The test specimen was introduced into a cylindrical-shaped cell and flooded by water under a stress corresponding to the weight of the piston. Once the swelling deformation was stabilized, loading was performed incrementally (50,100, 200 and $400 \mathrm{kPa}$ ) and was followed by unloading down to $50 \mathrm{kPa}$. Then loading was increased up to $800 \mathrm{kPa}$ and 
the sample was last unloaded. The measurement acquisition was made using several sensors connected to a data acquisition system (ELE Geotechnical Software DS7). The parameters to be derived from the compressibility curves of unsaturated soil are the initial void ratio $\left(\mathrm{e}_{0}\right)$, the compression index $(\mathrm{Cc})$ and the swelling coefficient $(\mathrm{Cs})$. The compression index $(\mathrm{Cc})$ is the slope of the second linear portion of the loading curve showing the void ratio (e) vs. the logarithm of the effective pressure (p). Cc specifies the sensitivity of soil compaction along that curve. The swelling coefficient (Cs) reports the susceptibility of a clayey soil swelling. It is the slope of linear part of the curve of the final unloading showing e vs. $\log (\mathrm{p})$.

\subsection{Results}

\subsubsection{Physical Tests}

Particle size curves are shown in Figure 2 and the results of the physical tests are listed in Table 1.

This table allows the following remarks:

- the clay fraction (<2 microns) is much lower for Lama2 and Lama3 compared to Lama1.

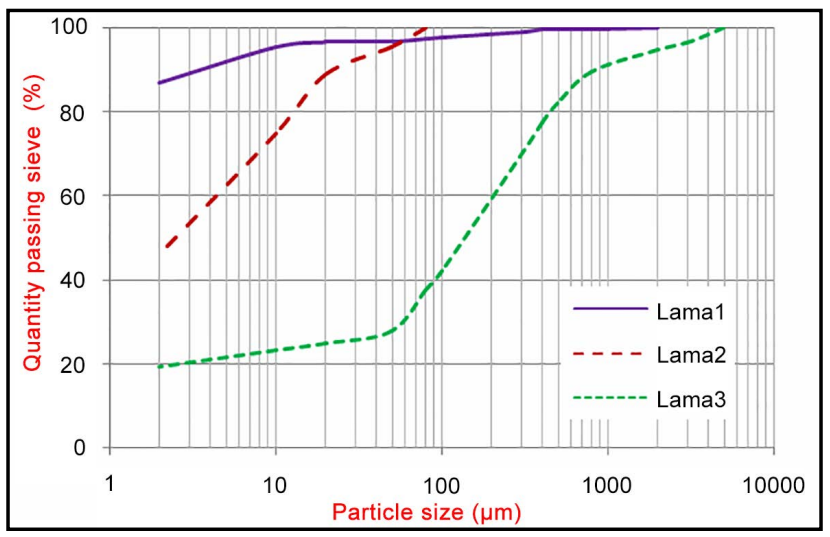

Figure 2. Particle size curves.

Table 1. Identification parameters.

\begin{tabular}{cccc}
\hline Geotechnical characteristics & Lama1 & Lama2 & Lama3 \\
\hline Fine fraction $\mathrm{P}_{80}(<80$ microns) & 97.26 & 100.00 & 37.58 \\
Clay fraction $\mathrm{P}_{2}(<2$ microns) & 87.05 & 46.00 & 19.35 \\
Moisture saturation & 47.88 & 112.14 & 17.06 \\
Liquid limit (wl) & 91 & 141 & 51 \\
Plasticity index (Ip) & 58 & 67 & 30 \\
Withdrawal limit ( $\left.\mathrm{w}_{\mathrm{R}}\right)$ & 8.5 & 38 & 8 \\
Linear shrinkage factor $(\mathrm{Rl})$ & 0.54 & 0.39 & 0.32 \\
Dry density & 1.18 & 0.87 & 1.85 \\
Blue value $(\mathrm{Vb})$ & 12 & 8.75 & 2.21 \\
USCS Classification $[13]$ & $\mathrm{CH}$ & $\mathrm{MH}$ & $\mathrm{SC}$ \\
\hline
\end{tabular}


- basically $100 \%$ of particles passed through a sieve of 80 microns for Lama2 and Lamal.

- Lama2 is very light as indicated by its dry density of 0.87 compared to Lama3 (1.85).

- Lama2 showed the highest liquid limit: 141 against 91 for Lama1 and 64 for Lama3.

- Lama1 is classified in the category of plastic clayey soils, Lama2 is a silt of high plasticity while Lama3 is a granulometry clayey sand.

Some authors managed to evaluate the swelling potential of soils from knowledge of their geotechnical characteristics including liquid limit (wl), plasticity index (Ip), withdrawal limit $\left(\mathrm{w}_{\mathrm{R}}\right)$, linear shrinkage factor $(\mathrm{Rl})$ and blue value $(\mathrm{Vb})$ [11] [14]. For Lama1 and Lama2 the swelling potential is considered "high to very high"; for Lama3, the potential is considered "medium".

\subsubsection{Free Swelling Test}

Results obtained by free swelling test are summarized in Table 2 .

Lama3 shows the heaviest with the lowest free swelling index, Lama1 has the highest value and Lama2 is compromised.

\subsubsection{Compressibility Tests}

Compressibility curves are shown in Figure 3 and Table 3 summarizes the different parameters deduced from these tests.

Table 2. Test results of free swelling test.

\begin{tabular}{cccc}
\hline Parameters & Lama1 & Lama2 & Lama3 \\
\hline Free swelling index (Fs) & 90.74 & 40.87 & 20.45 \\
\hline
\end{tabular}
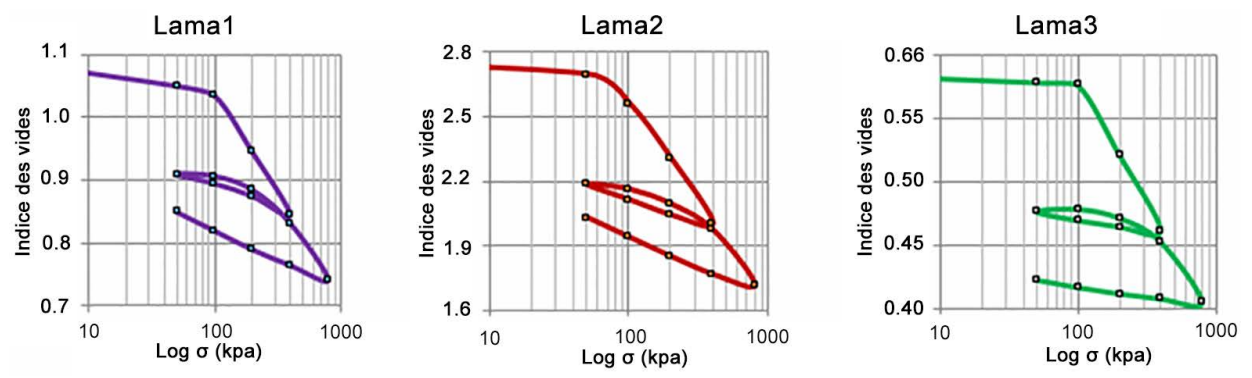

Figure 3. Compressibility curves.

Table 3. Compressibility parameters.

\begin{tabular}{cccc}
\hline Parameters & Lama1 & Lama2 & Lama3 \\
\hline Initial void ratio (e0) & 1.066 & 2.751 & 0.592 \\
Porosity $\left(n=\frac{e}{1+e}\right)$ & 0.516 & 0.733 & 0.372 \\
Compression Index (Cc) & 0.316 & 0.928 & 0.191 \\
Swelling Coefficient (Cs) & 0.094 & 0.292 & 0.017 \\
Cc/Cs & 3.35 & 3.18 & 11.24 \\
\hline
\end{tabular}


Compared to Lama1 and Lama3, the void ratio value for Lama2 is very important, which leads to the highest values for compression index (Cc) and swelling coefficient

(Cs). However, the ratio $\frac{C c}{C s}$ is virtually the same for Lama1 and Lama2.

\subsection{Synthesis}

All these results based on macroscopic observations revealed therefore an unexpected behavior for Lama1 and Lama2, which could not be explained by only geotechnical and standard classification of clayey soils. Indeed, the results of the free swelling test are not in line with the results of physical testing and compressibility testing. Lamal shows the highest free swelling index while the compressibility tests reveal that Lama1 has moderate swelling coefficient Cs. Lama2 behaves the reverse way and shows a moderate free swelling index (Fs) and a quite high swelling coefficient (Cs). In addition, Lama2 shows the highest plasticity index. Last, the compressibility tests lead to a similar $\frac{C c}{C s}$ ratio for Lama1 and Lama2. So, under "free swelling conditions" (free swelling index), Lama1 swells more than Lama2 does. When loading and unloading the samples, an opposite trend is observed: Lama2 swells (Cs) more than Lama1 does. The $\frac{C c}{C s}$ ratio being the same for the two samples, Lama2 is more compressible (Cc) than Lama1. As the samples are actually natural clayey soils, one may assert that one component entering in the composition of the samples is responsible for the observed trends. In this respect, the samples are investigated at the microscopic scale in the next section with special emphasis given to their mineralogical composition and their microstructure.

\section{Microscopic Characterization}

\subsection{Methods}

Several complementary methods of analysis were performed in order to explain the different trends reported above.

\subsubsection{Differential Thermal Analysis and Thermal Gravimetric Analysis}

The analyses were carried out simultaneous between $30^{\circ}$ and $1000^{\circ} \mathrm{C}$ under a stream of argon using a NETZSCH STA 409 device. The heating rate was $10^{\circ} \mathrm{C} / \mathrm{min}$. The thermocouple is of $S$ type supporting alumina crucibles of $50 \mu$, scanned at a rate of 60 $\mathrm{ml} / \mathrm{min}$ with argon.

\subsubsection{Chemical Analysis}

Mass content of chemical elements were determined with an Inductively Coupled Plasma-Optical Emission Spectrometer (ICP-OES) at the "Service d'Analyse, des Roches et des Minéraux (SARM)" of Nancy on the fine fraction (diameter $<80$ microns). Test specimens were fused in Pt crucibles along with ultra-pure $\mathrm{LiBO}_{2}$ at $980^{\circ} \mathrm{C}$ and were passed into a motorized tunnel oven at constant speed during 60 minutes [15]. The quantification of the elements is based on the principle of nebulization and ioniza- 
tion of the sample liquid (acidic solution treatment) in an argon plasma $\left(6000^{\circ} \mathrm{C}\right.$ $\left.8000^{\circ} \mathrm{C}\right)$.

\subsubsection{X-Ray Diffraction}

Soil mineralogy was also determined by X-ray diffraction (XRD) analysis. The spectra were collected on a PANalitycal PW3020 Bragg-Brentano $\theta$ - $2 \theta$ geometry diffractometer equipped with a secondary monochromator over an angular range $2 \theta=3^{\circ}-80^{\circ}$. The Cu-Ka Diffraction was generated at $45 \mathrm{kV}$ and $40 \mathrm{~mA}$ (lambda $=0.15418 \mathrm{~nm}$ ). Peaks present in these diagrams were identified using the embedded database (the "Powder Diffraction File") under the EVA processing software. The semi-quantification of the mineral composition as derived from the diffraction peak area was made using the EVA software BRUKER-AXS ${ }^{\circledR}[16]$.

\subsubsection{Environmental Scanning Electron Microscopy (ESEM) and X-Ray Energy Dispersive Spectrometry (EDS)}

Secondary electrons and backscattered electrons images were obtained (in low vacuum) using a Field Emission Gun (FEG) FEI Quanta 250 Environmental Scanning Electron Microscope (ESEM). Semi-quantitative chemical analyses using an Edax Apollo XL Xray Energy Dispersive Spectrometer (EDS) were performed to complete the mineral characterization. For every sample, a 2D X-ray map was acquired over the whole surface of the sample with the EDS spectrometer. X-ray mapping consisted in rastering over the whole map area storing the entire spectral information for every pixel location in the image. From these X-ray data, reconstitution of the main mineral phases using a statistical method available under the EDAX Genesis Software was made.

\subsection{Results}

\subsubsection{Differential Thermal Analysis (DTA) and Thermal Gravimetric Analysis} (TG)

The DTA and TG curves are shown in Figure 4. For Lama1 the DTA curve showed essentially peak at $485^{\circ} \mathrm{C}$ characteristic of kaolinite and a peak at $766^{\circ} \mathrm{C}$ characteristic of smectite. Lama2 DTA curve showed two mains peaks $\left(124^{\circ} \mathrm{C}\right.$ and $\left.484^{\circ} \mathrm{C}\right)$ below $600^{\circ} \mathrm{C}$ which are characteristic of fibrous clays [17] [18]. For Lama3, we note on the DTA curve a peak at $491^{\circ} \mathrm{C}$ corresponding to kaolinite. This curves suggested that the three samples do not include the same clays. The analyses presented in what follows aimed at identifying the presence of other compounds such as silica, oxides that are expected to enter into the composition of these clayey soils.

\subsubsection{Chemical Analysis}

The results obtained on the three samples are summarized in Table 4.

The quantification of the ICP-OES data highlighted themajor components in their oxidized forms: $\mathrm{SiO}_{2}, \mathrm{Al}_{2} \mathrm{O}_{3}, \mathrm{Fe}_{2} \mathrm{O}_{3}, \mathrm{MgO}$ and $\mathrm{H}_{2} \mathrm{O}$. The lower $\mathrm{H}_{2} \mathrm{O}$ and $\mathrm{MgO}$ content in Lama3 compared to Lama1 and Lama2 supports the DTA results: a clay content for Lama3 dominated by kaolinite and a clay content for Lama1 and Lama 2 dominated by smectite and fibrous clay, respectively. Note that the higher content in iron oxides and 
titanium oxides that typifies Lama3 strengthens the mechanical properties of this clayey soils.
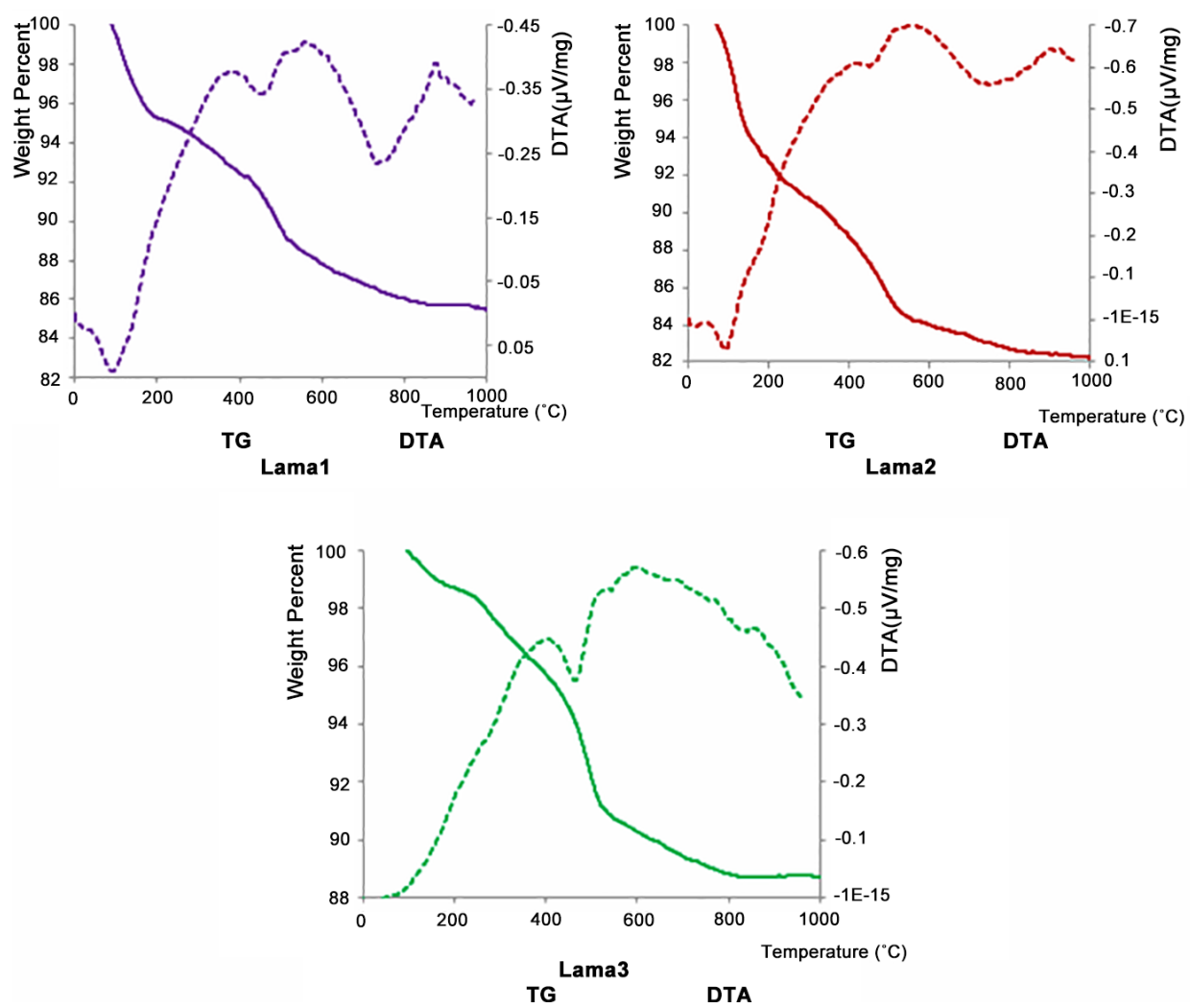

Figure 4. Thermo gravimetric analysis (TG) and differential thermal analysis (DTA) curves.

Table 4. Chemical composition of the studied clayey soils (ICP-OES).

\begin{tabular}{cccc}
\hline & \multicolumn{3}{c}{ Weight percentage } \\
\cline { 2 - 4 } Elements & Lama1 & Lama2 & Lama3 \\
\hline $\mathrm{SiO}_{2}$ & 50.40 & 51.12 & 55.43 \\
$\mathrm{Al}_{2} \mathrm{O}_{3}$ & 16.87 & 15.27 & 16.79 \\
$\mathrm{Fe}_{2} \mathrm{O}_{3}$ & 7.43 & 5.30 & 10.85 \\
$\mathrm{MgO}$ & 1.72 & 5.73 & 0.46 \\
$\mathrm{CaO}$ & 1.44 & 0.67 & 0.95 \\
$\mathrm{Na}_{2} \mathrm{O}$ & 0.07 & 0.08 & 0.10 \\
$\mathrm{~K}_{2} \mathrm{O}$ & 0.17 & 0.66 & 0.25 \\
$\mathrm{MnO}$ & 0.09 & 0.09 & 0.11 \\
$\mathrm{TiO}_{2}$ & 1.17 & 0.73 & 1.25 \\
$\mathrm{P}_{2} \mathrm{O}_{5}$ & 0.06 & 0.18 & 0.40 \\
$\mathrm{H}_{2} \mathrm{O}$ & 20.25 & 19.58 & 12.82 \\
$\mathrm{Total}$ & 99.65 & 99.40 & 99.39 \\
\hline
\end{tabular}




\subsubsection{X-Ray Diffraction}

The acquired X-ray diffraction patterns are shown in Figure 5. The diffractograms indicated that the main minerals are: quartz, kaolinite, palygorskite, smectite, and goethite.

With the EVA software, the relative abundance of each identified mineral was estimated semi-quantitatively taking into account the net area of the peaks in the diffraction pattern. According to this method, the samples were characterized as follow:

- Lama1: $40 \%$ of quartz, $41 \%$ of smectite, $14 \%$ of kaolinite, $3 \%$ of goethite and $2 \%$ of anatase.

- Lama2: $86 \%$ of palygorskite, $7 \%$ of kaolinite, $3 \%$ of smectite, $2 \%$ of quartz, and $2 \%$ of muscovite.

- Lama3: $55 \%$ of quartz, $39 \%$ of kaolinite, and $6 \%$ of goethite.

Lama3 is clearly a mix of quartz and kaolinite enriched in iron oxides (goethite $\mathrm{FeO}(\mathrm{OH})$ ). This is consistent with its low free swelling index (Fs) and its low compression index (Cc) and swelling coefficient (Cs) compared to the other samples (Lama1 and Lama2). XRD result also reveals that Lama2 basically is a clay mixture largely dominated by palygorskite which is a fibrous clay. At the opposite, Lamal is a clayey soil dominated by quartz and smectite.

\subsubsection{Environmental Scanning Electrum Microscopy (ESEM) and X-Ray Energy Dispersive Spectrometry (EDS)}

ESEM images along with the corresponding X-Ray EDS chemical maps are shown in Figures 6-8.

Figure 6(b) is a low magnification BSE image of Lama1 revealing a granular arrangement. The statistical analysis of the X-Ray EDS mapping data determined two main phases (Figure $6(\mathrm{c})$ ). The mineralogical interpretation of the quantification on the

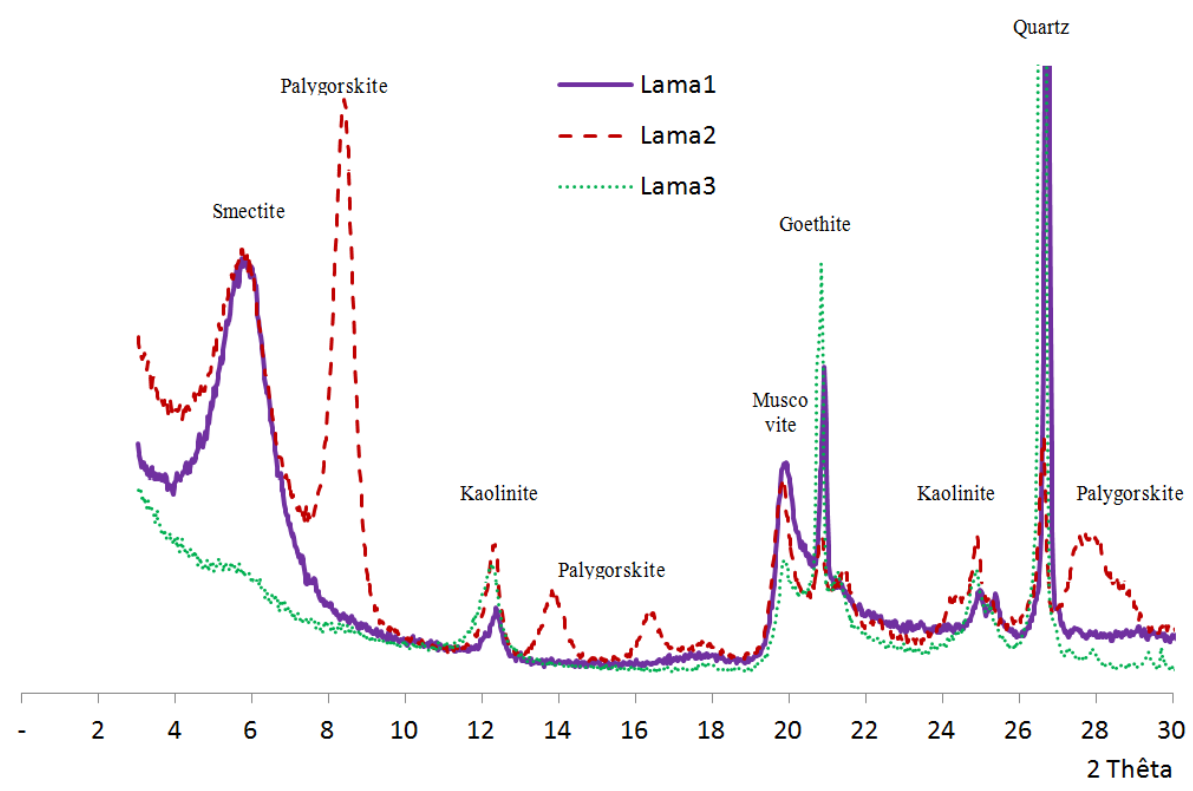

Figure 5. X-Ray Diffraction patterns of the three samples. 


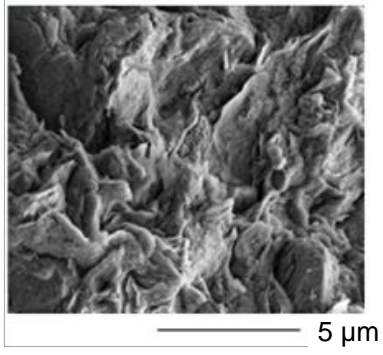

(a)

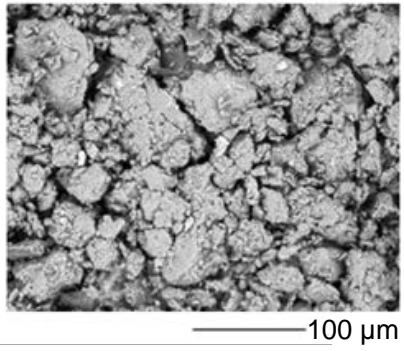

(b)

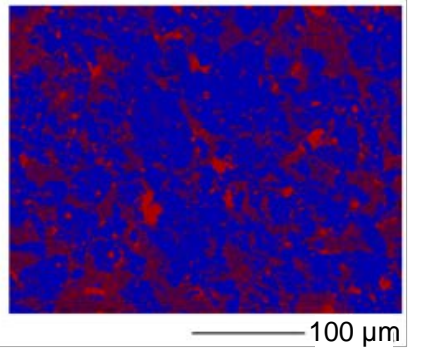

(c)

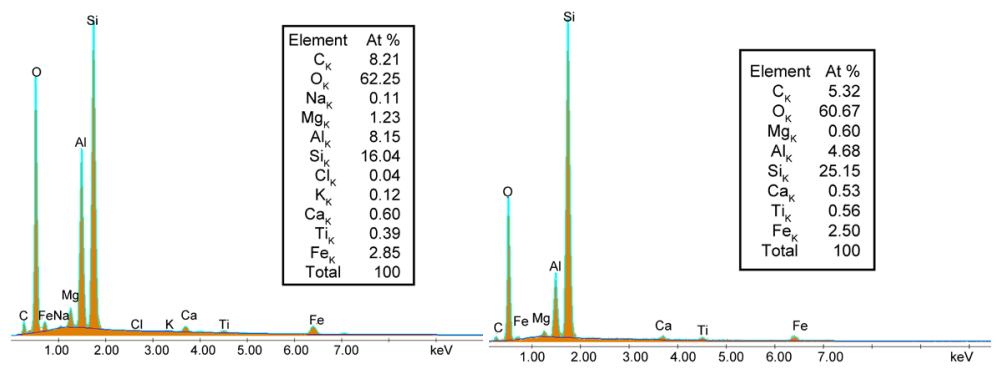

(d)

(e)

Figure 6. Sample Lama1. (a) Secondary Electron (SE) high magnification image; (b) Back Scattered Electrons (BSE) low magnification image; (c) Statistical analysis of the X-ray spectral mapping data; (d) Average phase spectrum of the dominant phase (blue pattern in (c); (e) Average phase spectrum of the second phase (red pattern in (c)).

phase spectrum Figure 6(d) of the blue phase in Figure 6(c) shows clearly that the phase is dominated by a smectite (phase area\%: 81) of stoichiometry ( $\mathrm{Na}, \mathrm{Ca})_{0.2}(\mathrm{Al}$, $\mathrm{Mg})_{2.3} \mathrm{Si}_{4} \mathrm{O}_{10}(\mathrm{OH})_{2} \cdot 2 \mathrm{H}_{2} \mathrm{O}$ along with a bit of goethite $(8,5)$. The high magnification images within the blue phase cf. e.g., Figure 6(a), show the typical honeycomb structure of a smectite. The mineralogical interpretation of the phase spectrum (Figure 6(e)) of the red phase in Figure 6(c) reveal phase dominated by quartz (phase area\%: 61) along with kaolinite and a bit of goethite.

Figure 7(b) is a low magnification BSE image of Lama2. When zooming within this image, a fibrous structure with quite large inter fiber voids cf. e.g., Figure 7(a), is systematically seeing. This explain the very low density of this sample (Table 1 ). The statistical analysis of the X-ray EDS mapping data reveals quite consistently a single phase represented in blue in Figure 7(c) (the green patterns represent inter particle voids not accessible to the X-ray analysis due to an important relief). The phase spectrum of this blue phase is given in Figure 7(d) along with the atomic \% quantification. The mineralogical interpretation reveals unambiguously that this blue phase is an almost pure palygorskite.

The low magnification BSE image in Figure 8(b) of Lama3 shows a heterogeneous structure including large grains intermingled within a more continuous matrix. The high resolution image within the "matrix" Figure 8(a) shows a booklet-shaped particle whose texture supports the matrix is made up of kaolinite (as supported by XRD and DTA data). The statistical analysis of the X-Ray EDS mapping data highlights two main 


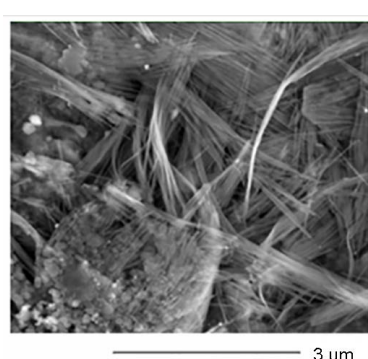

(a)

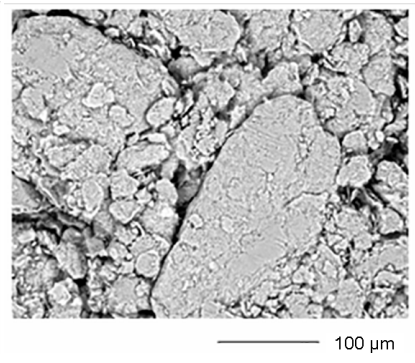

(b)

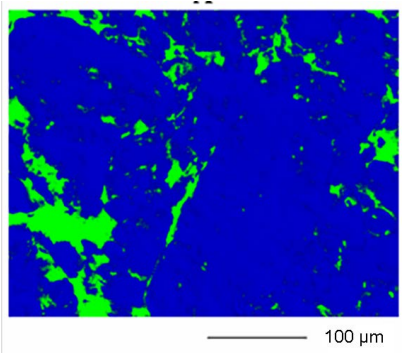

(c)

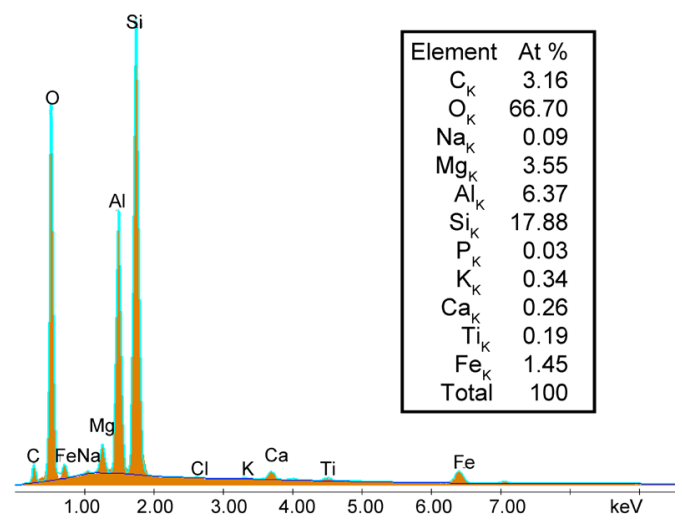

(d)

Figure 7. Sample Lama2. (a) SE high magnification image; (b) BSE low magnification image; (c) Statistical analysis of the X-ray spectral mapping data; (d) Average phase spectrum of the dominant phase (blue pattern in (c)).
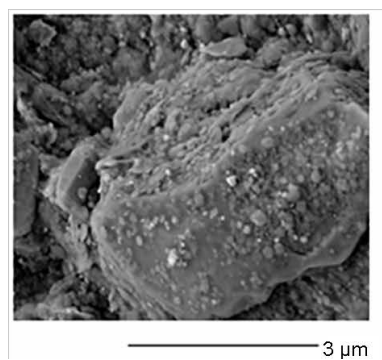

(a)

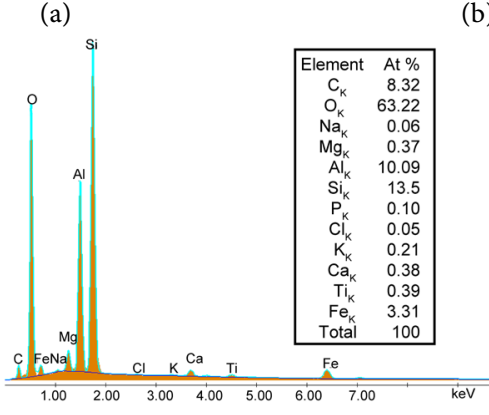

(d)

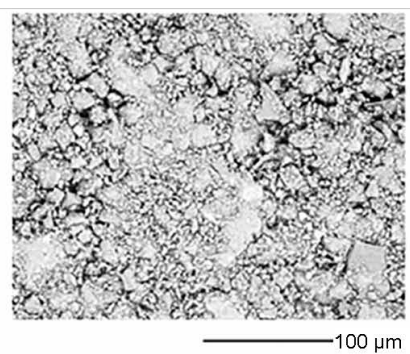

(b)

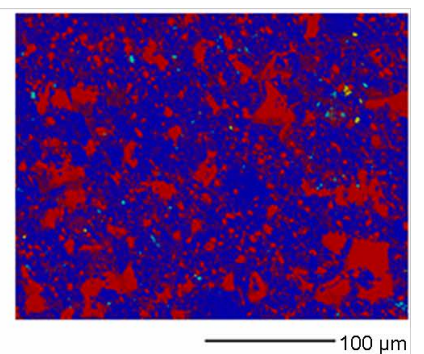

(c)

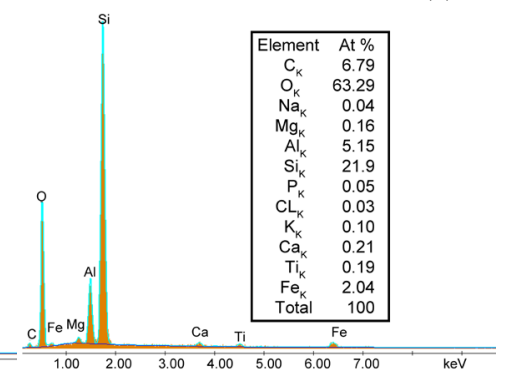

(e)

Figure 8. Sample Lama3. (a) SE high magnification image; (b) BSE low magnification image; (c) Statistical analysis of the X-ray spectral mapping data; (d) Average phase spectrum of the blue phase in (c); (e) Average phase spectrum of the second phase (red pattern in (c)). 
phases represented in blue and red in Figure 8(c). The spectrum associated to the blue phase in Figure 8(c) is provided in Figure 8(e) along its atomic \% quantification. The mineralogical interpretation of At $\%$ quantification shows unambiguously that the blue phase is dominated by kaolinite (phase area\%: 66) along with quartz (10\%) and goethite $(10 \%)$. The red phase is dominated by quartz (phase area \%: 50.5) along with kaolinite (33.5\%) and goethite (6.1\%).

\section{Discussion}

By combining thermal analysis, ICP-OES chemical analysis, XRD characterization, SEM observations complementary X-ray EDS analyses, the mineral components of the three soils have been identified. Lama1 is a clayey soil containing predominately quartz grain, smectite and goethite. Lama2 is basically a fibrous clay, namely palygorskite. Lama3 is a clayey soil in the form of a mix of quartz and kaolinite along with goethite.

Smectite, palygorskite and kaolinite are all phyllosilicate. Kaolinite is nonswelling and palygorskite is typified by a moderate swelling capacity, whereas smectite is a swelling clay. More precisely, smectite have very weak interlayer boards and have the property of binding water molecules between two adjacent layers. The water in the clay particles is arranged into monolayers [19]. Such intra particle swelling takes place therefore at a very fine intra particle scale but has a large scale expression. This distinction feature is responsible for the very high free swelling index (Fs) of Lama1 compared to Lama2 and Lama3. Kaolinite has a low shrinkage-swelling capacity due to very strong hydrogen bonds between the layers, which furthermore allow large stacks of sheets. This property combined with the presence of quartz explain the low free swelling index (Fs) and the low compression index (Cc) and swelling coefficient (Cs) that typified the compressibility test for this clayey soil. At the very fine scale, fibrous clays like palygorskite exhibit a hollow bricks structure, which forms channels. Palygorskite is a modulated phyllosilicate made up of layer ribbons connected by tetrahedral inversion resulting in zeolite like tunnels [20]. The distinctive feature of these minerals is that they show a three-dimensional structure compared to the other phyllosilicate. Therefore, swelling of fibrous clays is limited [21]. This property explains that Lama2 shows an intermediate free swelling index compared to Lama1 and Lama3. Note that at a larger scale cf. e.g. Figure 7(a), Lama2 shows large inter fiber voids that can be filled with water. Such inter fiber water contributes to the free swelling index (Fs) of Lama2 but its macroscopic expression remains moderate compared to that one of a swelling clay like smectite. For Lama1 and Lama2, the trends observed for the free swelling test change during the compressibility test. The relatively low values of Cc and Cs for Lamal is mainly explained by the role played by the packing of quartz grains which limits the compressibility under loading and expansion during unloading. Goethite, which binds quartz grains, acts in the same way. The quite large values of $\mathrm{Cc}$ and $\mathrm{Cs}$ for Lama2 is chiefly the consequence of the inter fiber porosity which is quite high. The high Cc of Lama2 is due to a loss of porosity during loading and its high Cs is due to that inter fiber voids are partly recovered during unloading. In other words, for Lamal the quartz grains binder goethite acts 
as a reinforcing frame. The geotechnical properties are therefore mostly explained by the quartz stiffness rather than by the swelling clay. For Lama2, it is both the inter fiber porosity and the clay self that explain the high values for $\mathrm{Cc}$ and $\mathrm{Cs}$.

\section{Conclusions}

Geotechnical tests on three clayey soils reveal the results of physical and compressibility tests appear not to be consistent with the free swelling test results. These natural clayey soils showing a different microscopic characterization: indeed, the microscopic analyses that were performed allowed to specify the nature of the clay minerals that compose them. Likewise, the X-ray EDS chemical mapping revealed the dominant mineralogical phases in every soil and explained the behavior of the samples at the macroscopic level. As to the mineralogy, the studied samples turned out to be principally three types of clay minerals: palygorskite, smectite and kaolinite. In terms of swelling mineral content, Lama3 was the one of the lowest content.

The behaviors of Lama1 and Lama2 were compared by focusing on compressibility, free swelling and physical tests, which highlighted differences in the behaviors of the two samples. The above coupled analysis highlighted some important relationships between their underlying microscopic and their geotechnical properties. Altogether, from the geotechnical point of view, Lama1 (dominantly smectite) and Lama2 (fibrous) behaved as a clayey soils but showed contrasting mechanical/geotechnical properties, which were difficult to understand consistently from the only geotechnical viewpoint. Important differences between Lama1 and Lama2 were revealed from the viewpoint offered by thermal analysis, ICP-OES chemical analysis, XRD characterization, SEM observations complementary X-ray EDS analyses. These differences at the microscopic scale did explained the different trends observed at the macroscopic scale.

To complete this study that combines microscopic and macroscopic aspects of clayey soils, other samples will be subjected to various tests. From the data that are thus formed, a classification of clayey soils, based on the free swelling test can be developed.

\section{Acknowledgements}

The authors wish to express their thanks to the X-ray Service of the Institute of Condensed Matter Chemistry of Bordeaux (ICMCB-CNRS). As to the equipment used for the microscopic analyses, the authors thank the European Union, which promotes the Aquitaine region (France) with the European Regional Development (FEDER) Fund.

\section{References}

[1] Langroudi, A. and Yasrobi, S. (2009) A Micro-Mechanical Approach to Swelling Behavior of Unsaturated Expansive Clays under Controlled Drainage Conditions. Applied Clay Sciences, 45, 8-19. http://dx.doi.org/10.1016/j.clay.2008.09.004

[2] Ferber, V., Auriol, J.C., Cui, Y.J. and Magnan, J.P. (2009) On the Swelling Potential of Compacted High Plasticity Clays. Engineering Geology, 104, 200.

http://dx.doi.org/10.1016/j.enggeo.2008.10.008

[3] Jahangir, E., Deck, O. and Masrouri, F. (2013) An Analytical Model of Soil-Structure Inte- 
raction with Swelling Soils during Droughts. Computers and Geotechnics, 54, 16-32. http://dx.doi.org/10.1016/j.compgeo.2013.05.009

[4] Chen, F.H. and Ma, G.S. (1987) Swelling and Shrinkage Behavior of Expansive Clays. 6th International Conference Expansive Soils, New Delhi, 127-129

[5] Dif, A.E. and Bluemel, W.F. (1991) Expansive Soils under Cyclic Drying and Wetting. Geotechnical Testing Journal, 14, 96-102. http://dx.doi.org/10.1520/GTJ10196J

[6] Saiyouri, N., Hicher, P.Y. and Tessier, D. (2000) Microstructural Approach and Transfer Water Modelling in Highly Compacted Unsaturated Swelling Clays. Mechanics of Cohesive-Frictional Materials, (NAG. International Journal of Numerical and Analytical Methods in Geomechanics), 5, 41-60.

http://dx.doi.org/10.1002/(SICI)1099-1484(200001)5:1<41::AID-CFM75>3.0.CO;2-N

[7] Williams, A.B. and Donaldson, G.W. (1980) Developments Relating to Building on Expansive Soils in South Africa. Proceedings of the 4th Conference on Expansive Soils, Denver, Vol. 2, 834-844.

[8] Fleureau, J.M., Kheirbek-Saoud, S., Soemitro, R. and Taibi, S. (1993) Behavior of Clayey Soils on Drying-Wetting Paths. Canadian Geotechnical Journal, 30, 287-296.

http://dx.doi.org/10.1139/t93-024

[9] Yazdandoust, F. and Shahaboddin, Y.S. (2010) Effect of Cyclic Wetting and Drying on Swelling Behaviour of Polymer-Stabilized Expansive Clays. Applied Clay Science, 50, 461468. http://dx.doi.org/10.1016/j.clay.2010.09.006

[10] Haas, H., Maubec, N., Bruyère, D., Le Clech, A. and Bourrat, X. (2015) Test de la mesure de l'indice de gonflement des sols par immersion dans l'eau pour la caractérisation du retraitgonflement de sols naturels. Symposium International SEC 2015, Paris.

[11] Prian, J.P., Donsimoni, M. and Vincent, M. (2000) Cartographie de l'aléa retraitgonflement des argiles dans le département de l'Essonne. Rapport BRGM No. RP-50376-FR. 273 p.

[12] Volkoff, B. and Willaime, P. (1976) Notice Explicative No. 66. Carte pédologique de reconnaissance de la République Populaire du Bénin à 1/200.000. Feuille de Porto-Novo. ORSTOM.

[13] Holtz, D.R. and Kovacs, D.W. (1981) An Introduction to Geotechnical Engineering. Prentice-Hall, Inc.

[14] Chen, F.H. (1988) Foundations on Expansive Soils. Elsevier Publisher B.V.

[15] Carignan, J., Hild, P., Mevelle, G., Morel, J. and Yeghicheyan, D. (2001) Routine Analyses of Trace Element in Geological Samples Using Flow Injection and Low Pressure On-Line Liquid Chromatography Coupled to ICP-MS: A Study of Geochemical Reference Materials BR, DR-N, UB-N, AN-G and GH. Geostandards Newsletter, 25, 187-198. http://dx.doi.org/10.1111/j.1751-908X.2001.tb00595.x

[16] Smith, D.K., Johnson, G.G., Ruud, J. and Clayton, O. (2001) Clay Mineral Analysis by Automated Powder Diffraction Analysis Using the Whole Diffraction Pattern. Powder Diffraction, 16, 181-185. http://dx.doi.org/10.1154/1.1423284

[17] El Faleh, E.M., Taibi, M., Elamane, M. and Mahdoudi, M.L. (2002) Etude PhysicoChimique de la Palygorskite du Moyen-Atlas. Annales de Chimie Science des Matériaux, 27, 15-25. http://dx.doi.org/10.1016/S0151-9107(02)80015-0

[18] Yan, W., Liu, D., Tan, D., Yuan, P. and Chen, M. (2012) FTIR Spectroscopy Study of the Structure Changes of Palygorskite under Heating. Spectrochimica Acta Part A, 97, 10521057. http://dx.doi.org/10.1016/j.saa.2012.07.085

[19] Nowamooz, H. (2007) Retrait/Gonflement des sols argileux compactés et naturels. Thèse de 
doctorat de l'Institut, National Polytechnique de Lorraine, Lorraine.

[20] Galan, E. (1996) Properties and Applications of Palygorskite-Sepiolite Clays. Clay Minerals, 31, 443-453. http://dx.doi.org/10.1180/claymin.1996.031.4.01

[21] Volle, N. (2011) Nano-Hybrides élastomères à propriétés contrôlées par fonctionnalisation spécifique d'une argile de type sépiolite: renfort et couleur. Thèse de l'Université Nice, Sophia Antipolis.

Submit or recommend next manuscript to SCIRP and we will provide best service for you:

Accepting pre-submission inquiries through Email, Facebook, LinkedIn, Twitter, etc. A wide selection of journals (inclusive of 9 subjects, more than 200 journals)

Providing 24-hour high-quality service User-friendly online submission system

Fair and swift peer-review system Efficient typesetting and proofreading procedure

Display of the result of downloads and visits, as well as the number of cited articles Maximum dissemination of your research work

Submit your manuscript at: http://papersubmission.scirp.org/

Or contact jmmce@scirp.org 